\title{
STRATEGI BAURAN PEMASARAN SAYURAN DALAM MENINGKATKAN MINAT BELI KONSUMEN
}

\author{
Rofinus Kanisius Wangge ${ }^{1}$, Sarlina Noni ${ }^{2}$ \\ ${ }^{1,2}$ Program Studi Agribisnis Fakultas Pertanian Universitas Nusa Nipa

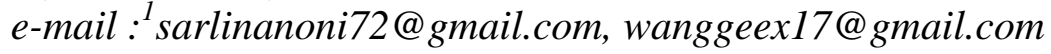

\begin{abstract}
ABSTRAK
Tujuan penelitian ini adalah untuk melihat strategi penerapan bauran pemasaran sayuran produksi kebun Fakultas Pertanian Nusa Nipa dalam meningkatkan minat beli konsumen. Hasil penelitian: konsumen memiliki kemampuan yang berbeda-beda dalam menyebutkan karakteristik atau atribut dari produk-produk tersebut. Konsumen berusaha memuaskan suatu kebutuhan dengan penerapan bauran pemasaran untuk minat beli :1). Produk sayuran organik yang berada di Kebun Fakultas Pertanian Universitas Nusa Nipa, sangat beragam, yaitu: bawang merah, cabe rawit, tomat, pepaya, semangka, mentimun, sawi dan kangkung. Produk yang beragam sangat mempengaruhi minat konsumen karena produk tersebut memberikan banyak manfaat bagi kesehatan, hal ini sangat menarik bagi konsumen yang akan memutuskan membeli dan mengkonsumsi produk yang mereka inginkan, 2). harga yang ditentukan atau harga penjualan dari produk sayuran bisa dijangkau oleh para konsumen atau ibu rumah tangga, membeli dengan harga terjangkau tapi memiliki manfaat yang besar, bagi diri sendiri, keluarga masyarakat dan kehidupan. 3). Lokasi kebun yang sangat strategis, terletak di pinggir jalan dan mudah dijangkau para pelanggan atau konsumen. 4). Mempromosikan sayuran organik dilakukan baik secara lisan maupun secara tertulis juga melalui melalui whats App dan facebook.
\end{abstract}

Kata kunci : bauran pemasaran, minat beli konsumen

\section{ABSTRACT}

The purpose of this study is to look at the implementing of marketing mix of vegetbles from Agriculture Faculty University of Nusa Nipa in increasing consumer buying interest. The results of the study: consumers have different abilities in mentioning the characteristics or attributes of these products. Consumers try to satisfy a need by implementing a marketing mix for buying interests :1). Organic vegetable products located in the Garden faculty of agriculture, University of Nusa Nipa, very diverse, namely: onion, cayenne pepper, tomato, papaya, watermelon, cucumber, mustard and kale. Diverse products greatly influence consumer interest because the product has many health benefits, this is very attractive for consumers who will decide to buy and consume the product they want, 2). The specified price or sales price of vegetable products can be reached by consumers or housewives, buying at an affordable price but has great benefits, for yourself, family communities and life. 3). the location of the garden is very strategic, located on the side of the road and easily reachable to customers or consumers. 4). Promoting Organic Vegetables is done either orally or in writing also through whats App and facebook.

Keywords : marketing mix, consumer buying interests 


\section{PENDAHULUAN}

Strategi adalah suatu rencana yang fundamental untuk mencapai tujuan perusahaan. Definisi lain menyebutkan bahwa strategi adalah keseluruhan konsep untuk bagaimana sebuah perusahaan mengatur dirinya sendiri dan semua kegiatan dengan tujuan agar bisnis yang kita jalankan berhasil, melakukan persaingan, dan memberikan imbal hasil yang superior kepada pemegang saham.

Bauran pemasaran sangat penting untuk diterapkan dalam berbagai usaha baik produk barang atau jasa untuk dapat mengetahui apakah yang akan ditawarkan mampu dipasarkan dan dijadikan alternative dalam melakukan pengambilan keputusan (Gita, 2015). Menurut (Kotler, 2000). Bauran pemasaran merupakan variabel-variabel terkendali yang dapat digunakan perusahaan untuk mempengaruhi konsumen dari segmen pasar tertentu yang dituju perusahaan. Keunggulan kompetitif yang harus dicapai saat ini banyak yang menggunakan bauran pemasaran 7P (Abubakar, 2015).

Indonesia merupakan negara yang mempunyai potensi yang berlimpah dibidang sumberdaya alam hampir disemua sektor, salah satunya adalahsektor pertanian. Sektor pertanian adalah sektor yang dominan di Indonesia sebagai negara yang berbasis agraris. Hal tersebut jelas terlihat dari mayoritas penduduk Indonesia yang berprofesi sebagai petani. Sektor pertanian merupakan sektor strategis dan potensial dalam pembangunan ekonomi nasional. Oleh karena itu, pembangunan pertanian perlu mendapat perhatian yang lebih baik, sekalipun prioritas pada kebijaksanaan industrialisasi sudah dijatuhkan, namun sektor pertanian dapat memiliki kemampuan untuk menghasilkan surplus (Mawarni dkk, 2017).

Kabupaten Sikka merupakan salah satu Kabupaten di Provinsi Nusa Tenggara Timur Indonesia, yang sebagian besar penduduknya memiliki mata pencaharian sebagai petani. Salah satu usaha pertanian di Kabupaten Sikka adalah pertanian tanaman bawang merah, dengan luas lahan sawah sebesar 26 Ha (Kantor Dinas Pertanian Kabupaten Sikka (2019).

Kebun Praktek Fakultas Pertanian Unipa Maumere merupkan salah satu lokasi praktek bagi mahasiswaa pertanian yang berlokasi Di Jalan Litbang, Kelurhan Kota Uneng, Kecamtan Alok, Kabupaten Sikka. Lahan tersebut di gunakan untuk budidaya tanaman pangan dan holtikulltura. Kegiatan yang di lakukan di lahan ini di lakukkan selama beberpa musin cukup intesif tanpa diikuti dengan kesesuaian terhadap suatu jenis tanaman ini akan berdampak pada pendapatan secara ekonomis dan pendapatan yang diperoleh tdak akan meningkat. dengan cara ini maka akan diketahui pontesi atau kelaslahan untuk tipe penanaman. Produk sayuran organik yang di tanam di kebun fakultas adalah: bawang merah, cabai rawit, pepaya, semangka, mentimun, sawi dan kangkung.

\section{METODOLOGI PENELITIAN}

Penelitian dilakukan di Kebun Praktek Fakultas Pertanian Universitas Nusa Nipa pada bulan Desember 2020.

\section{Teknik Analisis Data}

Dalam penelitian ini menggunakan analisis data kualitatif yang bersifat induktif, yaitu suatu proses analisis berdasarkan data yang diperoleh secara langsung yang 
selanjutnya dikembangkan menjadi hipotesis. Setelah data terkumpul langkah selanjutnya adalah mengklasifikasikan sesuai dengan permasalahan yang diteliti, kemudian data-data tersebut disusun dan dianalisis dengan metode analisis data kualitatif deskriptif.

\section{Analisis Deskriptif Kualitatif}

Merupakan penelitian yang
digunakan untuk menyelidiki,
menemukan, menggambarkan, dan
menjelaskan kualitas atau keistimewaan
dari pengaruh sosial yang tidak dapat di
jelaskan, diukur atau digambarkan
melalui pendekatan kuantitatif

(Saryono, 2010).

\section{III.HASIL DAN PEMBAHASAN}

\section{Penerapan Bauran Pemasaran}

Sebagai seorang konsumen, sangat baik jika memiliki pemikiran tentang sehatnya pemenuhan konsumsi bagi keluarganya, dimana keluarga dapat mengkonsumsi produk organik sebagai pelengkap dalam menu kesehariannya. Salah satu menu konsumsi adalah sayuran, oleh sebab itu diharapkan mendapatkan produk sayuran yang organik, dimana dengan mengkomsumsi produk sayuran organik membebaskan keluarganya dari pengaruh bahan kimia dan dapat menambah atau mempertahankan kesehatan keluarganya, seperti yang diungkapkan oleh Bapak Paskalis Wolo: Memiliki dorongan motivasi akan hidup sehat yang untuk seluruh keluarganya dengan mengkonsumsi sayuran organik, sejak kebun Fakultas berproduksi. Juga Ibu Anita Moy : Dan dengan konsumsi sayuran organik selain memberikan manfaat yang baik untuk tubuh, juga menjadikan anakanak semakin cerdas.
Produk sayuran organik yang berada di Kebun Fakultas Pertanian Universitas Nusa Nipa Indonesia, sangat beragam, yaitu: bawang merah, cabe rawit, tomat, pepaya, semangka, mentimun, sawi dan kangkung. Produk yang beragam akan mempengaruhi minat konsumen karena produk yang bervariasi akan memberikan persepsi yang lebih lengkap dan menarik bagi konsumen yang akan memutuskan membeli produk yang mereka inginkan.

Produk dalam istilah pemasaran (Marketing) adalah bentuk fisik barang yang ditawarkan dengan seperangkat citra (Image) dan jasa (Service) yang digunakan untuk memuaskan kebutuhan konsumen. Menurut (Kismono, 2001), hal ini sejalan dengan penelitian yang dilakukan oleh (Mardhikasari, 2014), yang berjudul Pengaruh Store Atmosphere, Lokasi Toko, dan Keragaman Produk Terhadap Keputusan Pembelian Konsumen Mirota Kampus yang melakukan studi kasus pada Mahasiswa Fakultas Ekonomi UNY. Penelitian tersebut memiliki persamaan dalam segi (variabel keberagaman produk dan minat beli) dan dari hasil pengujian hipotesis menunjukkan bahwa keberagaman produk berpengaruh positif terhadap keputusan pembelian konsumen.

\section{Harga (Price)}

Harga yang ditentukan atau harga penjualan dari produk sayuran di Kebun Fakultas Pertanian Kebun Universitas Nusa Nipa, bisa dijangkau oleh para konsumen atau Ibu Rumah Tangga. Membeli dengan harga terjangkau tapi memiliki manfaat yang besar, bagi diri sendiri, keluarga masyarakat dan kehidupan. Sayuran atau produk tanaman dapat dibeli oleh para konsumen selain langsung di beli 
di Lokasi Kebun, dapat juga dibeli di Pasar Alok yang merupakan pasar tradisional di Kota Maumere yang berdampingan atau berdekatan dengan lokasi kebun tersebut. Menurut pendapat Bapak Fransiskus dan Ibu Yuliana Nona Ina.

Hal ini sejalan dengan pendapat (Swastha, 2003), Harga merupakan komponen yang berpengaruh langsung terhadap proses penentuan dimana seorang akan berbelanja. Penetapan harga itu sendiri cukup kompleks dan sulit. harga, nilai dan faedah (Utility) merupakan konsep-konsep yang sangat berkaitan. Utility adalah atribut suatu produk yang dapat memuaskan kebutuhan. Sedangkan nilai adalah ungkapan secara Kuantitatif tentang kekuatan barang untuk menarik barang lain dalam pertukaran.

\section{Tempat (Place)}

Kebun Fakultas Pertanian Fakultas Pertanian Universitas Nusa Nipa treletak di pinggir jalan, sehingga mudah untuk ke lokasi kebun untuk membeli sayur organik yang banyak manfaat untuk kesehatan tubuh, Menurut pendapat Ibu Yani Wunu, hal serupa juga dikatakan oleh Ibu Anastasia Dere: hasil sayur di Kebun Fakultas Pertanian Universitas Nusa Nipa Indonesia sangat banyak, harga yang baik dan tidak mahal, kami dapat membeli untuk sayur di rumah, di pinggir jalan sehingga membuat banyak orang dengan mudah datang untuk mmbeli dan membuat mata sejuk karena keindahan warna yang hijau.

Hal ini sejalan dengan Penelitian yang dilakukan oleh (Eko Purnomo, 2016), yang berjudul "Pengaruh Harga, Kualitas Produk Dan Lokasi Terhadap Minat Beli Konsumen Dalam Membeli Beras Lokal." Menyatakan bahwa hasil dari uji T (Parsial) bahwa lokasi secara parsial berpengaruh Terhadap Minat Beli Konsumen Dalam Membeli Beras Lokal. Penelitian yang dilakukan oleh (Oetomo, 2012) mengenai Analisis Pengaruh Keragaman Menu, Persepsi Harga Dan Lokasi Terhadap Minat Beli Ulang Konsumen (Studi pada Restoran Waroeng Taman Singosari Semarang). Dengan hasil uji hipotesis menunjukkan bahwa Lokasi berpengaruh signifikan terhadap minat beli pada Restoran Waroeng Taman Singosari Semarang.

\section{Promosi (Promotion)}

Dalam mempromosikan Sayuran Organik Dari Kebun Fakultas Pertanian Universitas Nusa Nipa Indonesia, banyak dilakukan baik secara lisan maupun secara tertulis.Hasil promosi tersebut membuat banyak konsumen dalam hal ini ibu rumah tangga yang datang membeli sayuran tersebut. Bapak Argan Eduardo : saya menjual sayuran organik dari Kebun Fakultas Pertanian Fakultas Pertanian Universitas Nusa Nipa Indonesia, sangat baik untuk kesehatan, demikian juga Bapak Hironimus : Ia memberitahukan kepada para pembeli sayur atau konsumen bahwa sayuran ini adalah hasil dari Kebun Fakultas Pertanian Fakultas Pertanian Universitas Nusa Nipa Indonesia dan menggunakan pupuk organik, sedangkan Bapak Fransiskus Riki AlsonSaya mempromosikan sayuran organik ini melalui whats App dan facebook.

Keberadaan produk di pasar dapat diketahui masyarakat melalui komunikasi yang dilakukan oleh produsen. Adapun yang dimaksud adalah dengan adanya promosi yang merupakan salah satu bagian dari bauran pemasaran. Kotler (2005), alatalat promosi yang dapat digunakan 
perusahaan dalam mengkomunikasikan produk meliputi iklan, promosi penjualan, hubungan masyarakat dan pemberitaan, penjualan pribadi, dan pemasaran langsung. Juga menurut (Gitosudarmo, 2014), bahwa promosi merupakan kegiatan yang ditujukan untuk mempengaruhi konsumen agar mereka dapat menjadi kenal akan produk yang ditawarkan oleh Perusahaan kepada mereka, yang kemudian mereka menjadi senang lalu membeli produk tersebut.

Hal ini sejalan dengan penelitian Dewi Diniaty (2014), dengan judul Perancangan Strategi Pemasaran Pada Produk Anyaman Pandan, menyatakan bahwa promotion (promosi) dan produk memiliki nilai koefisien terbesar dan memiliki hubungan positif dan signifikan. Hal ini membuktikan bahwa faktor promosi dan produk mempunyai pengaruh yang besar terhadap minat beli konsumen.

\section{Strategi Penerapan Bauran Pemasaran Dalam Meningkatkan Minat Beli Konsumen}

Sayuran organik sebagai salah satu produk yang dihasilkan dari pertanian bersifat ramah lingkungan dan lebih mendekatkan diri kepada konsep alam, sehingga mampu memberikan jaminan kualitas yang lebih baik dibandingkan dengan sayuran biasa. Hal tersebut menimbulkan daya tarik tersendiri bagi konsumen kelas tertentu yang kemudian mengubah pola konsumsi sayurannya dari sayuran yang dibudidayakan secara anorganik ke sayuran organik, sehingga daya tarik dan popularitas sayuran yang diusahakan secara anorganik berkurang bagi konsumen kelas tertentu. Hal ini disebabkan dengan meningkatnya tingkat pendapatan dan pengetahuan akan pentingnya makanan yang aman bagi kesehatan dan ramah lingkungan.

Produk sayuran yang dijual selalu segar dimana para konsumen biasa langsung datang membeli di lokasi kebun Fakultas Pertanian Kebun Universitas Nusa Nipa Indonesia.

Minat beli produk sayuran organik di Kebun Fakultas Pertanian Kebun Universitas Nusa Nipa Indonesia, sangatlah tinggi. Hal ini dapat dilihat dari jasil penjualan yang dilakukan perhari dalam jumlah produksi. Para konsumen datang membeli biasanya dapat dilakukan secara perorangan atau juga dilakukan secara berkelompok atau bersama-sama keluarga atau teman. Dengan melihat tingginya minat beli para konsumen mengakibatkan bertambah besarnya peluang pasar bagi produk sayuran organic tersebut. Para karyawan atau pegawai yang bekerja di kebun tersebut termotivasi untuk selalu giat bekerja, karena merasa senang akan terjualnya hasil produksi tersebut.

Segala usaha pasti memiliki kendala yang selalu menjadi hambatan untuk perkembangan usaha yang sedang dilakukan oleh perusahaan. Kendala tersebut harus bisa dipecahkan, apabila dibiarkan maka usaha tersebut tidak akan bertahan lama (bangkrut). Kendala tersebut apabila dapat terpecahkan maka usaha tersebut akan berkembang. Kendala yang dihadapi kebun Fakultas Pertanian Universitas Nusa Nipa adalah dalam pemasaran sayuran organik, dalam penelitian ini dapat dilihat dari segi internal dan eksternal. (Gitosudarmo, 2000), menyatakan bahwa salah satu faktor yang menyebabkan kurang efektif yaitu tenaga kerja. Kendala yang dihadapi oleh kebun praktek adalah jumlah tenaga kerja yang masih kurang. Dengan kurangnya tenaga kerja 
berdampak pada volume hasil produksi yang dihasilkan. Banyak minat pembeli untuk membeli dan mengkonsumsi sayuran organik, tapi kenyataan masih banyak pembeli atau konsumen tidak dapat memperolehnya karena sayuran organik tersebut sudah laku terjual.

Diniaty (2014), menyatakan bahwa promotion (promosi) dan produk memiliki nilai koefisien terbesar dan memiliki hubungan positif dan signifikan. Hal ini membuktikan bahwa faktor promosi dan produk mempunyai pengaruh yang besar terhadap minat beli konsumen.

Hal ini sejalan dengan penelitian yang dilakukan oleh Utami (2017) tentang Pengaruh Harga dan Kualitas Produk Terhadap Minat Beli Sayuran Organik di Pasar Sambas Medan yang menyatakan bahwa hasil dari uji $\mathrm{T}$ (parsial) bahwa harga berpengaruh secara parsial terhadap minat beli sayuran organik di Pasar Sambas Medan.

\section{KESIMPULAN}

Berdasarkan hasil penelitian dan pembahasan tentang Strategi Penerapan Bauran Pemasaran (Marketing Mix) Dalam Meningkatkan Minat Beli Konsumen Pada Kebun Fakultas Pertanian Kebun Universitas Nusa Nipa Indonesia, maka dapat diambil kesimpulan sebagai berikut: Konsumen memiliki kemampuan yang berbedabeda dalam menyebutkan karakteristik atau atribut dari produk-produk tersebut. Konsumen berusaha memuaskan suatu kebutuhan dengan mencari manfaat tertentu dari solusi produk.

\section{DAFTAR PUSTAKA}

Arikunto. 2002. Prosedur Penelitian Suatu Pendekatan Praktek, Jakarta:

\section{Rineka Cipta,}

Diniaty, D \& Agusrinal, A. 2014. Perancangan Strategi Pemasaran Pada Produk Anyaman Pandan. SITEKIN: Jurnal Sains, Teknologi dan Industri Vol 11 No 2 tahun 2014.

Durianto, D. 2013. Strategi Menaklukan Pasar Melalui Riset Ekuitas dan Perilaku. Jakarta: Gramedia Pustaka Utama.

Ferdinand, A. 2002. Pengembangan Minat Beli Merek Ekstensi. Semarang: Badan Penerbit Universitas Diponegoro

Haris, H. 2013. Wawancara Observasi dan Foccus Group, Jakarta : PT Raja Grafindo Persada.

Husaini Usman dan Purnomo Setiady Akbar. 2000. Metodologi Penelitian Sosial, Jakarta : Bumi Aksara.

Kotler, P., \& Armstrong, G. (2017). Prinsip-prinsip Pemasaran. Jakarta: Erlangga.

Kotler, P., \& Keller, K. L. (2016). Manajemen Pemasaran. Jakarta: Erlangga.

Mardalis. 1999. Metode Penelitian Suatu Pendekatan Proposal , Jakarta: Bumi Aksara.

Meleong. 2009. Metodologi Penelitian Kualitatif, Bandung : PT Remaja Rosdakarya.

Sugiyono. 2012. Memahami Penelitian Kualitatif, Bandung : Alfabeta.

Wahyu Purhantara. 2010. Metodologi Penelitan Kualitatif untuk Bisnis, Yogyakarta Graha Ilmu.

Swastha, B., \& Irawan.. 2008. Manajemen Pemasaran Modern. Yogyakarta: Liberty Offset

Sugiyono. 2014. Metode Penelitian 
Bisnis. Bandung: Alfabeta

Swasta, B \& Stanton, W. 2008. Prinsipprinsip Pemasaran. Jakarta: Erlangga

Swastha, B., \& Irawan. 2008. Manajemen Pemasaran Modern. Yogyakarta: Liberty Offset.

Swastha, B., \& Irawan. 2008.
Manajemen Pemasaran Modern. Yogyakarta: Liberty Offset.

Utami, Ruri P \& Hendra Saputra. 2017. Pengaruh Harga dan Kualitas Produk Terhadap Minat Beli Sayuran Organik di Pasar Sambas Medan. Jurnal NIAGAWAN Vol 6 No 2 tahun 2017. 